\title{
Profile control performance and field application of preformed particle gel in low-permeability fractured reservoir
}

\author{
Bin $\mathrm{Xu}^{1,2}$ (D) $\cdot$ Yan Wang ${ }^{2}$
}

Received: 4 September 2020 / Accepted: 13 November 2020 / Published online: 25 November 2020

(c) The Author(s) 2020

\begin{abstract}
Water well profile control is the main way to control water channeling in low-permeability fractured reservoirs, and preformed particle gels (PPGs) are commonly used. A preformed particle gel was prepared and the synthesis conditions were optimized. The temperature and salt resistant performance, plugging performance were investigated and the field application was tested. The results showed PPGs exhibited good temperature and salt resistant performance. PPGs with larger particle size showed greater plugging strength but shorter valid period. Field tests suggested that multiple rounds of profile control should be employed using PPGs with different particle sizes to achieve deep profile control.
\end{abstract}

Keywords Preformed particle gel · Low-permeability fractured reservoir · Profile control · Field application · Plugging strength

\section{Introduction}

Water production in oil-producing wells becomes more and more serious as the wells mature, especially in the exploitation of low-permeability fractured reservoir, such as water flooding, gas flooding and chemical flooding ( $\mathrm{Gu}$ et al. 2014; Xu 2017; Zhang et al. 2018).

Water well profile control is the main way to control water channeling in low-permeability fractured reservoirs. For low-permeability fractured reservoirs, a good profile control agent should have the following characteristics: injectable, good plugging performance, movable and pollution-free (Zhou et al. 2017). At present, the common profile control agents for fractured reservoirs include polymer gel ( $\mathrm{He}$ et al 2009; Lu et al 2010), preformed particle gel (PPGs) (Imqam et al 2017; Sun et al 2019), polymer microspheres (Hua et al 2014; Li et al 2019), etc. As to particles like PPGs or microspheres, it is required that the initial size of the profile control agent must be smaller than the pore throat diameter of the formation; the profile control agent must

Bin Xu

xubin@bzu.edu.cn; cnxubin@126.com

1 College of Chemical Engineering and Safety, Binzhou University, Binzhou 256600, China

2 Anhui Tianrun Chemical Industry Co., Ltd, Bengbu 233010, China expand and have certain elasticity, and can produce deformation and breakthrough under certain pressure, so as to have the advantages of good plugging performance to achieve deep profile control.

Before further injection implementation in oilfield, characterizing in situ rheology in porous media is critical (Santoso et al 2017, 2018, 2020) and a series of influencing factors on flow characteristics of injection fluid should be considered, such as Non-Newtonian behavior in porous media, possible injection issues in the wellbore, sheardependent viscosity and retention-agglomeration process at pore-scale (Torrealba et al. 2019; Zhang et al 2010). If the injected concentration or injection rate is too big, particles can buildup inside the pore throat, which can reduce the permeability of the reservoir (Santoso et al 2017).

In this paper, a preformed particle gel was prepared by solution polymerization and the synthesis conditions were optimized. The temperature and salt resistant performance, plugging performance were investigated through laboratory experiments and the field application was tested, as shown in Fig. 1. 


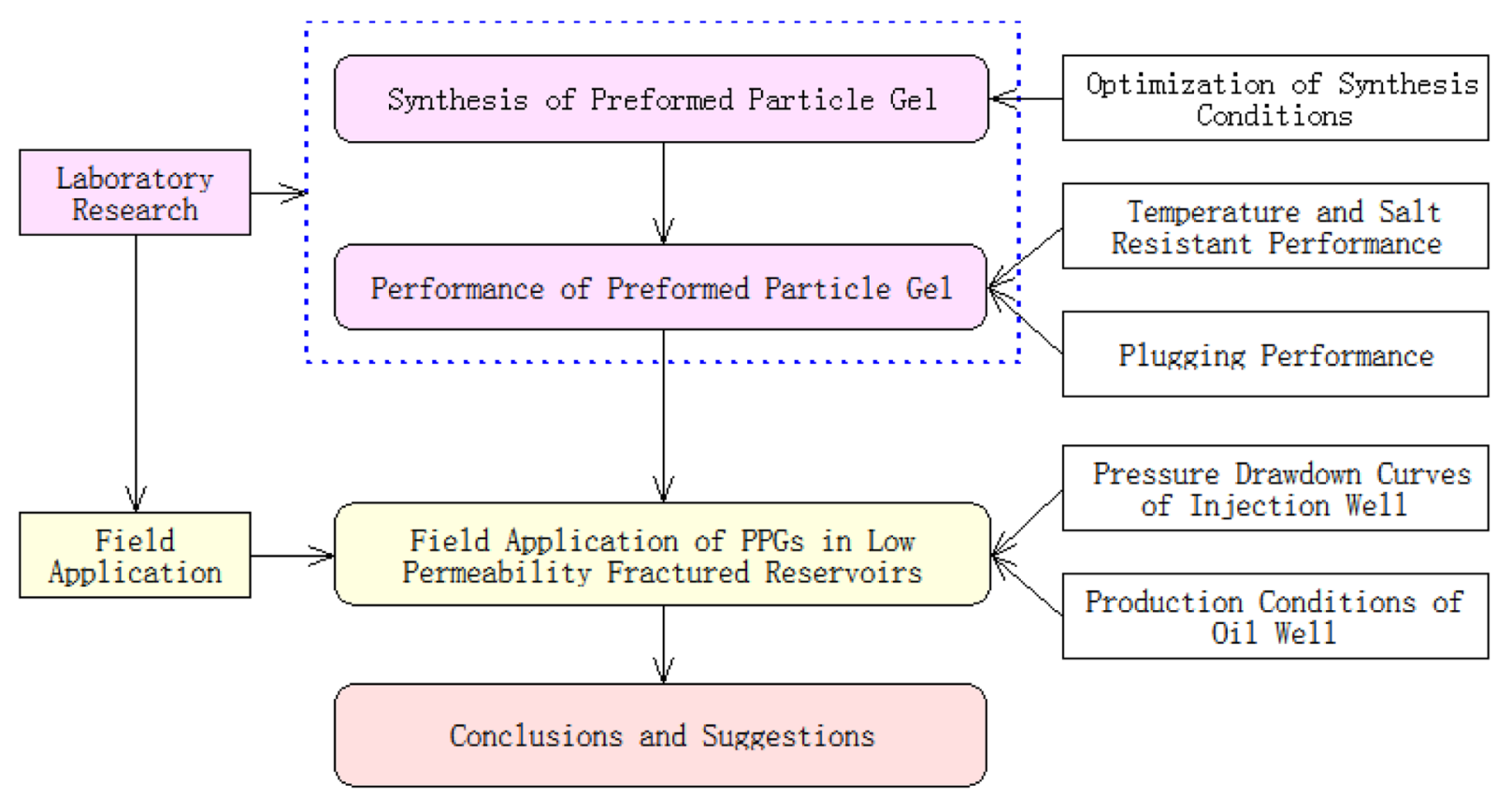

Fig. 1 The flowchart of our workflow

\section{Experimental}

\section{Materials}

Acrylamide (AM) was recrystallized twice from acetone and then dried under vacuum. Potassium persulfate (KPS) was used as the initiators, which was recrystallized from deionized water. N,N'-methylene bisacrylamide (MBAA) was used as the cross-linking agent. $\mathrm{Na}_{2} \mathrm{CO}_{3}, \mathrm{NaHCO}_{3}$, $\mathrm{NaCl}, \mathrm{CaCl}_{2}, \mathrm{MgCl}_{2}$ and $\mathrm{Na}_{2} \mathrm{SO}_{4}$ were used to simulate the formation water. All aqueous solutions were prepared using deionized water. All reagents were all analytical reagents obtained from Sinopharm Chemical Reagent Co., Ltd. (Shanghai, China).

The total salinity of the simulated formation water is $71,785 \mathrm{mg} / \mathrm{L} ; \mathrm{K}^{+}, \mathrm{Na}^{+} 17,305 \mathrm{mg} / \mathrm{L} ; \mathrm{Ca}^{2+} 8348 \mathrm{mg} / \mathrm{L}$; $\mathrm{Mg}^{2+} 458 \mathrm{mg} / \mathrm{L} ; \mathrm{Cl}^{-} 43,391 \mathrm{mg} / \mathrm{L} ; \mathrm{SO}_{4}{ }^{2-} 1920 \mathrm{mg} / \mathrm{L}$; $\mathrm{CO}_{3}{ }^{2-} 56 \mathrm{mg} / \mathrm{L} ; \mathrm{HCO}_{3}{ }^{-} 307 \mathrm{mg} / \mathrm{L}$.

\section{Synthesis of preformed particle gels}

PPGs were formed by acrylamide monomer adding crosslinking agent with the initiator of potassium persulfate to form a three-dimensional network structure (Imqam et al. 2015; Saghafi et al 2016; Heidari et al 2019). In this paper, MBAA was employed as the initiator. Sodium carbonate was added to hydrolyze it into negative electric hydrogel with carboxyl group. In order to improve the expansion ratio and temperature resistance of pre-cross-linking system, additives such as 2-Acrylamide-2-methylpro panesulfonic acid (AMPS) can be added.

\section{Performance evaluation of preformed particle gel}

\section{Expansion property}

The particle size of preformed particle gel was determined by laser particle size analyzer, and the expansion rate was defined as follows:

$S_{w}=\frac{D_{50}}{d}$

where $D_{50}$ indicates the corresponding particle size $(\mu \mathrm{m})$ of the PPGs in simulated formation water at certain conditions on the cumulative distribution curve when the probability is $50 \%$, while $\mathrm{d}$ indicates the average particle size $(\mu \mathrm{m})$ of dry particles.

\section{Plugging performance}

Core flooding device (as seen in Fig. 2) is used to evaluate the plugging performance of PPGs. The plugging performance is generally evaluated by plugging rate, breakthrough pressure gradient, etc.

\section{Plugging rate}




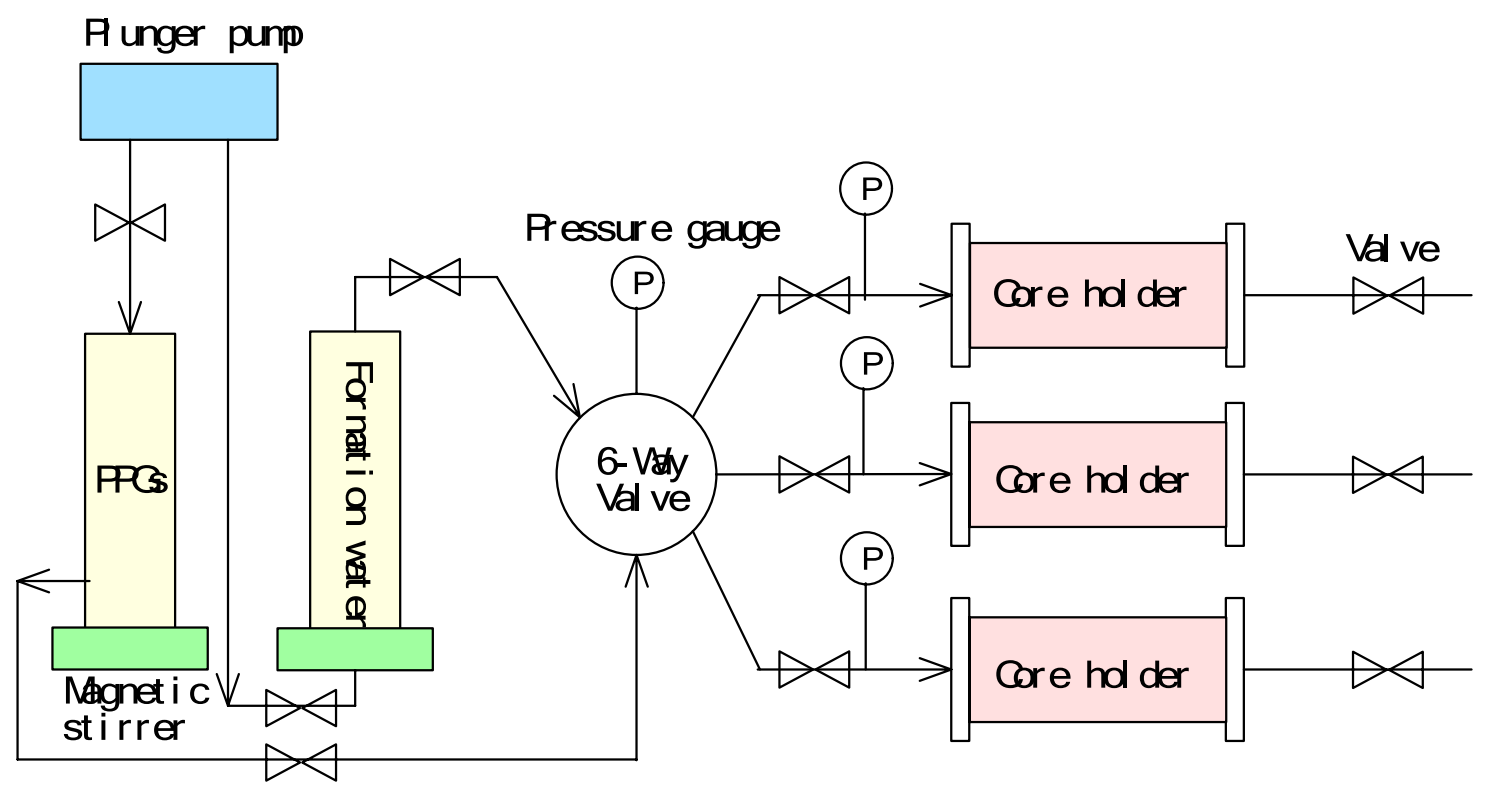

Fig. 2 Plugging performance experimental instrument of core test

$E=\left[1-\frac{K_{w b}}{K_{w a}}\right] \times 100 \%$

where $K_{w a}$ and $K_{w b}$ is the permeability before and after injection of PPGs.

\section{Breakthrough pressure gradient}

$P_{\max }=\frac{P_{0}}{L}$

where $P_{0}$ is the pressure difference at breakthrough and $\mathrm{L}$ is the length of experimental core.

\section{Results and discussion}

\section{Optimization of synthesis conditions of preformed particle gel}

The synthesis conditions of the PPgs were optimized by evaluating the expansion rate of PPGs in $10,000 \mathrm{mg} / \mathrm{L} \mathrm{NaCl}$ solution at $70{ }^{\circ} \mathrm{C}$ and the results were shown in Fig. 3. The optimized synthesis conditions were as follows: the cross-linker concentration, monomer concentration, initiator concentration and the reaction temperature were $0.06 \%, 20 \%, 0.5 \%$ and $60{ }^{\circ} \mathrm{C}$, respectively.

\section{Performance of preformed particle gel}

The temperature and salt resistant performance, plugging performance of PPGs were evaluated. The temperature and salt resistant performance of the PPGs was shown in Fig. 4. The PPGs exhibited good temperature and salt resistant performance, the expansion rate of PPGs remained above 10 in $100,000 \mathrm{mg} / \mathrm{L} \mathrm{NaCl}$ solution $\left(70{ }^{\circ} \mathrm{C}\right)$ or at the temperature of $130{ }^{\circ} \mathrm{C}(10,000 \mathrm{mg} / \mathrm{L} \mathrm{NaCl}$ solution $)$.

The plugging performance of PPGs was investigated with simulated artificial fractures by using quartz sand filling tube with larger particle size of 40 mesh, as shown in Table 1. In this test, the mass concentration of PPGs was $0.5 \%$, the injection rate was $1.0 \mathrm{~mL} / \mathrm{min}$ and the temperature was $70^{\circ} \mathrm{C}$, and the particle size of PPGs was 100-120 mesh and 200-230 mesh.

It can be seen from Table 1 that the PPGs have good plugging performance for fractures, and the plugging rate can reach more than $90 \%$. The larger the particle size, the greater the plugging strength and breakthrough pressure gradient. According to Tang's and Imqam's study, PPGs particles with larger particle size were more likely to retain in porous media (Tang et al 2004; Imqam et al 2017). Thus PPGs with larger particle size can exhibit greater plugging strength but difficult to achieve deep profile control which means shorter valid period in the profile control process.

\section{Field application of PPGs in low-permeability fractured reservoirs}

Field application of PPGs was conducted and the well location and reservoir properties were shown in Fig. 5. The reservoir properties were as follows: reservoir buried depth: $2246 \mathrm{~m}$; reservoir temperature: $70{ }^{\circ} \mathrm{C}$; Porosity: 10.8\%; Average permeability: $0.4 \times 10^{-3} \mu \mathrm{m}^{2}$; Fracture direction: 

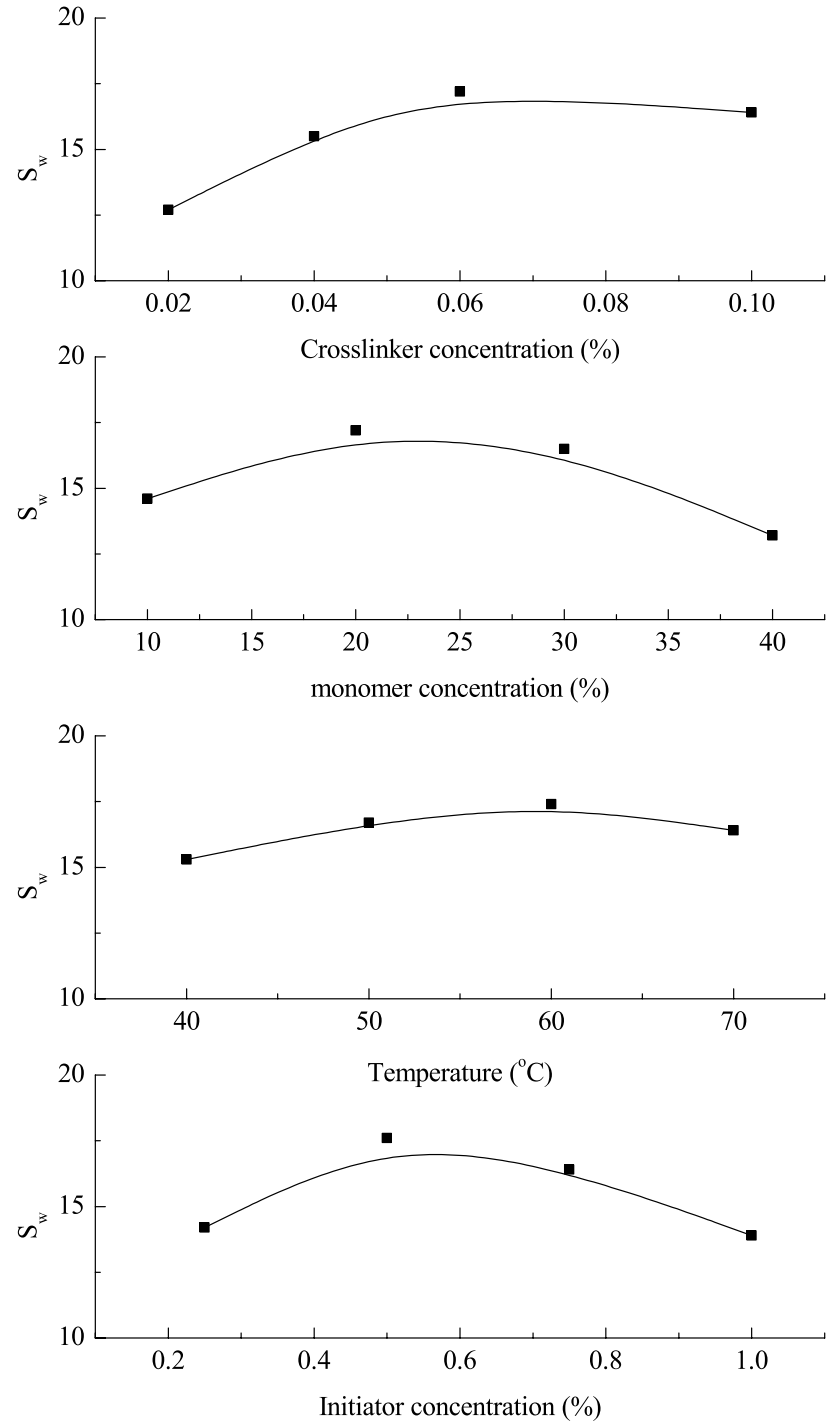

Fig. 3 Optimization of synthesis conditions of preformed particle gel

NE-SW; Fracture density: 0.38/m; Salinity: 71,785 mg/L, and the ionic composition was seen in Part 2.1; Total oil recovery: 7-8\%. Before field Application of PPGs injection, the three oil production wells were shut in because they were waterflooded. The PPGs injection was firstly carried out in the water injection well WW-1, and WW-1 and the oil production well OW-1 were of the key monitoring regions at the beginning of the field test. The monitoring process during the field test mainly includes two aspects: the pressure drawdown curves of injection well and the production conditions of the oil well such as the liquid production, oil production, water cut, chloride ion content, dynamic liquid level height, etc.

The water injection well WW-1 injected $10.1 \mathrm{t}$ PPGs with particles of $0.3-1.5 \mathrm{~mm}(30 \%)$ and $3-5 \mathrm{~mm}$ (70\%) in 3 days and the oil pressure increased from 15.1 to $19.2 \mathrm{MPa}$. The

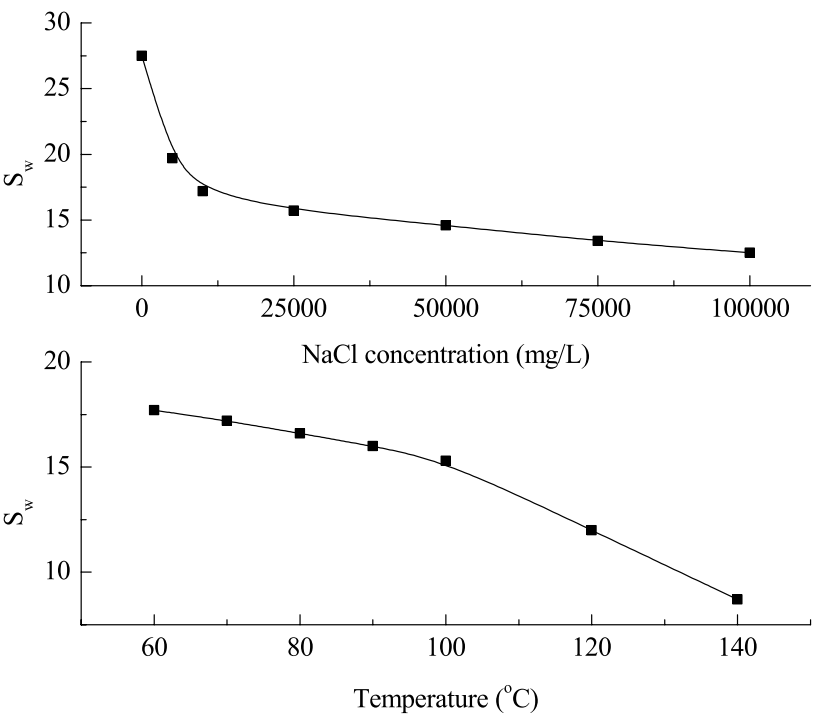

Fig. 4 The temperature and salt resistant performance of the PPGs

Pressure drawdown curves of injection well ww- 1 before and after profile control using PPGs were shown in Fig. 6. The pressure drop was faster after well shut before profile control which showed obvious water absorption characteristics in fractures; while after profile control, the pressure decreased slowly with time which proved that PPGs achieved good plugging effect for water injection well WW-1.

The water injection of WW-1 was resumed after profile control with an average daily injection volume of $10 \mathrm{~m}^{3}$. The production conditions of the horizontal oil well OW-1 after injection of PPGs were shown in Fig. 7. After profile control, the water content and liquid production decreased, while the oil production increased which showed that the PPGs effectively blocked the fractures. But water logging after 15 days showed that PPGs probably accumulated in the near well area of the water injection well and the injected water can break through the near well area and flowed into the communication fracture between oil and water wells, resulting in water logging of oil production well again. It is suggested that multiple rounds of profile control should be employed using PPGs with different particle sizes to achieve deep profile control.

\section{Conclusions}

(1) The synthesis conditions of the PPgs were optimized by evaluating the expansion rate and the optimized synthesis conditions were as follows: the cross-linker concentration, monomer concentration, initiator concentration and the reaction temperature were $0.06 \%, 20 \%, 0.5 \%$ and $60{ }^{\circ} \mathrm{C}$, respectively. 
Table 1 Plugging performance of preformed particle gels for fractures

\begin{tabular}{llllllll}
\hline No & Porosity (\%) & particle size (mesh) & PV & & $\begin{array}{l}\text { Permeability } \\
\left(\mathrm{um}^{2}\right)\end{array}$ & $\begin{array}{l}\text { Plugging } \\
\text { rate (\%) }\end{array}$ & $\begin{array}{l}\text { Breakthrough } \\
\text { pressure gradient } \\
(\mathrm{MPa} / \mathrm{m})\end{array}$ \\
\hline 1 & 34.2 & $100-120$ & 1 & 8.7 & 0.28 & 96.8 & 3.2 \\
2 & 35.6 & $200-230$ & 1 & 9.8 & 0.74 & 92.4 & 1.7 \\
\hline
\end{tabular}

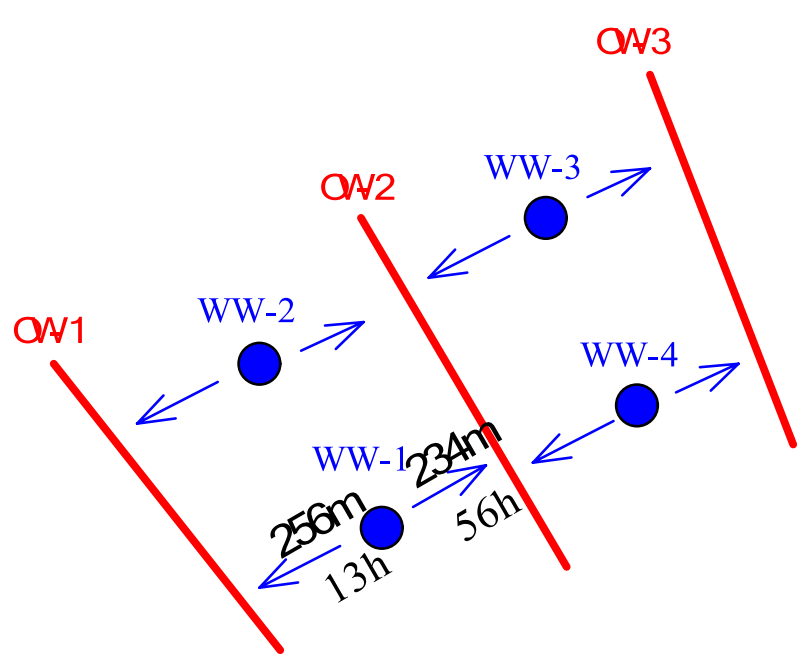

Fig. 5 Well location and reservoir properties of the PPGs field test block

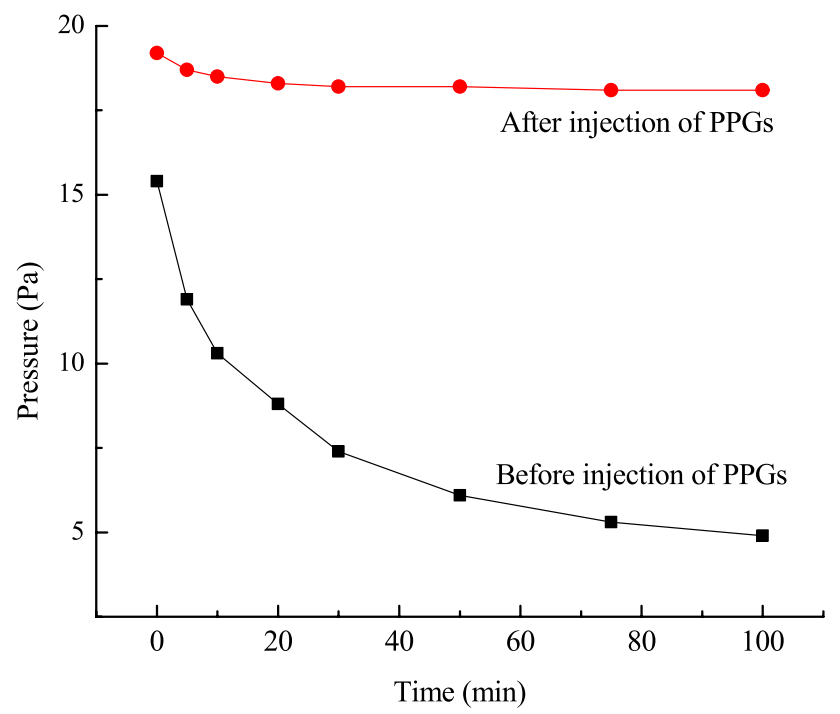

Fig. 6 Pressure drawdown curves of injection wells in profile control using PPGs

(2) The PPGs exhibited good temperature and salt resistant performance. PPGs with larger particle size can exhibit greater plugging strength but difficult to achieve deep

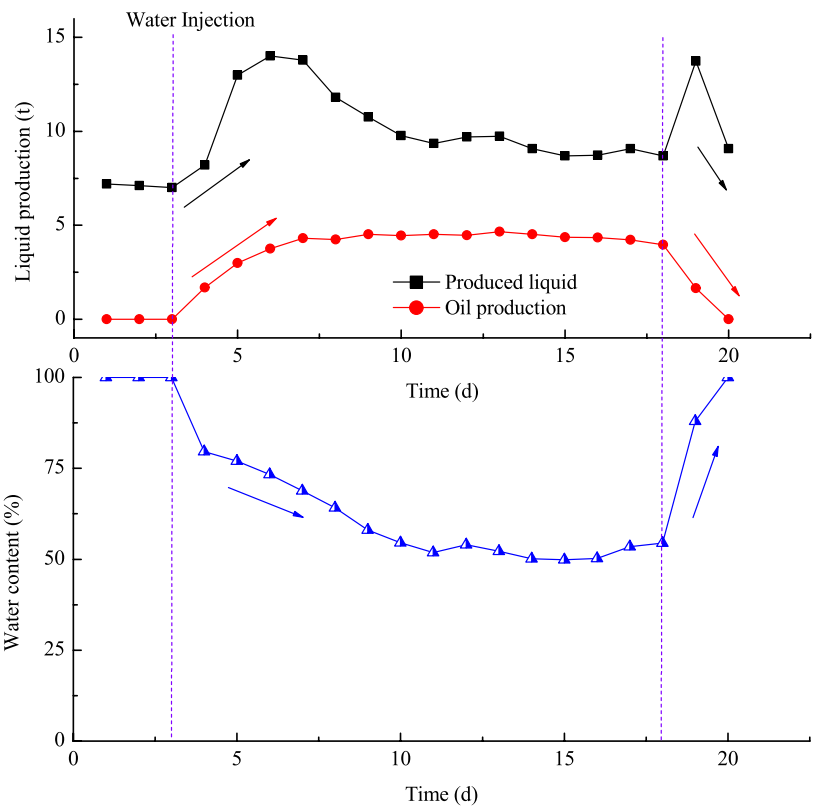

Fig. 7 The production conditions of oil well OW-1 after injection of PPGs

profile control which means shorter valid period in the profile control process.

(3) Field application of PPGs showed that PPGs achieved good plugging effect for water injection well. But PPGs probably accumulated in the near well area of the water injection well and the injected water can break through the near well area which resulting in water logging of oil production well again. So it is suggested that multiple rounds of profile control should be employed using PPGs with different particle sizes to achieve deep profile control.

Acknowledgements This work was supported by the Natural Science Foundation of Shandong Province of China under Grant [ZR2018QB007]; the Key Technology Research and Development Program of Shandong Province under Grant [2019GSF109117]; the Key Technology Research and Development Program of Anhui Province under Grant [1804a09020088].

Author contributions The submission has been received explicitly from all co-authors. And authors whose names appear on the submission have contributed sufficiently to the scientific work and therefore shared collective responsibility and accountability for the results. 
Funding This work was supported by the Natural Science Foundation of Shandong Province of China under Grant [ZR2018QB007]; the Key Technology Research and Development Program of Shandong Province under Grant [2019GSF109117]; the Key Technology Research and Development Program of Anhui Province under Grant [1804a09020088]. None of these organizations influenced the study design, the collection, analysis, and interpretation of data, the writing of the report, or the decision to submit the manuscript for publication.

\section{Compliance with ethical standards}

Conflict of interest The authors declare that they have no conflict of interest.

Ethical approval I certify that this manuscript is original and has not been published and will not be submitted elsewhere for publication. And the study is not split up into several parts to increase the quantity of submissions and submitted to various journals or to one journal over time. No data have been fabricated or manipulated (including images) to support the conclusions. No data, text, or theories by others are presented as if they were our own.

Open Access This article is licensed under a Creative Commons Attribution 4.0 International License, which permits use, sharing, adaptation, distribution and reproduction in any medium or format, as long as you give appropriate credit to the original author(s) and the source, provide a link to the Creative Commons licence, and indicate if changes were made. The images or other third party material in this article are included in the article's Creative Commons licence, unless indicated otherwise in a credit line to the material. If material is not included in the article's Creative Commons licence and your intended use is not permitted by statutory regulation or exceeds the permitted use, you will need to obtain permission directly from the copyright holder. To view a copy of this licence, visit http://creativecommons.org/licenses/by/4.0/.

\section{References}

Gu S, Liu Y, Chen Z, Ma C (2014) A method for evaluation of water flooding performance in fractured reservoirs. J Petrol Sci Eng 120:130-140

He Y, Xiong S, Yang Z, Ruan X, Gong Y (2009) The research on crosslinking polymer gel as in-depth profile control agent. Petrol Sci Technol 27(12):1300-1311

Heidari A, Vasheghani-Farahani E, Vafaie-Sefti M (2019) Preformed particle gels of sulfonated polyacrylamide: preparation, characterization, and application as permeability modifier. Iran Polym J 28(12):1001-1013

Hua Z, Lin M, Dong Z, Li M, Zhang G, Yang J (2014) Study of deep profile control and oil displacement technologies with nanoscale polymer microspheres. J Colloid Interf Sci 424:67-74

Imqam A, Bai B (2015) Optimizing the strength and size of preformed particle gels for better conformance control treatment. Fuel 148:178-185
Imqam A, Wang Z, Bai B (2017) The plugging performance of preformed particle gel to water flow through large opening void space conduits. J Petrol Sci Eng 156:51-61

Li J, Niu L, Lu X (2019) Migration characteristics and deep profile control mechanism of polymer microspheres in porous media. Energy Sci Eng 7(5):2026-2045

Lu X, Zhao L, Zhang K (2010) The effect and analysis on $\mathrm{Cr}^{3+}$ gel improving profile control in alkalescent alkaline/surfactant/polymer flooding. J Appl Polym Sci 112(5):2773-2780

Saghafi HR, Naderifar A, Gerami S, Farasat A (2016) Performance evaluation of viscosity characteristics of enhanced preformed particle gels (PPGs). Iran J Chem Chem Eng 35(3):83-92

Santoso, R., Rachmat, S., Putra, W.D.K., Resha, A.H., Hartowo H. (2017). Transport and retention modelling of Iron Oxide nanoparticles in core scale porous media for electromagnetic heating well-stimulation optimization. IOP Conf. Series: Materials Science and Engineering 214: 012017.

Santoso R, Fauzi I, Hidayat M, Swadesi B, Aslam BM, Marhaendrajana T (2018) Study of Non-Newtonian fluid flow in porous media at core scale using analytical approach. Geosystem Engineering 21(1):21-30

Santoso R, Torrealba V, Hoteit H (2020) Investigation of an improved polymer flooding scheme by compositionally-tuned slugs. Processes 8(2):197

Sun L, Han Q, Li D, Zhang X, Pu WF, Tang X, Zhang Y, Bai B (2019) Water plugging performance of preformed particle gel in partially filled fractures. Ind Eng Chem Res 58(16):6778-6784

Tang X, Liu Y, Liu G, Li L, Bai B, Cai L (2004) Methodology applied for property evaluation of pregelled particles (In Chinese). Oil Drill Product Technol 26(4):72-75

Torrealba VA, Hoteit H (2019) Improved polymer flooding injectivity and displacement by considering compositionally-tuned slugs. J Petrol Sci Eng 178:14-26

$\mathrm{Xu} \mathrm{B}$ (2017) $\mathrm{CO}_{2}$ miscible flooding in low permeability sandstone reservoirs and its influence on crude oil properties. Petrol Sci Technol 35(21):2024-2029

Zhang, T., Davidson, D., Bryant, S.L., Huh, C. (2010). Nanoparticlestabilized emulsions for applications in enhanced oil recovery. In proceedings of the SPE improved oil recovery symposium, Tulsa, OK, USA, 24-28 April 2010.

Zhang L, Zhang J, Wang Y, Yang R, Zhang Y, Gu J, Zhang M, Ren S (2018) Experimental investigation of low salinity water flooding in a low-permeability oil reservoir. Energ Fuel 32(3):3108-3118

Zhou Z, Zhao J, Zhou T, Huang Y (2017) Study on in-depth profile control system of low-permeability reservoir in block H of Daqing oil field. J Petrol Sci Eng 157:1192-1196

Publisher's note Springer Nature remains neutral with regard to jurisdictional claims in published maps and institutional affiliations. 